\title{
Sexo Casual: Motivações, Atitudes e Comportamentos de Homens e Mulheres Heterossexuais Adultos
}

\author{
Liliana Liviano Wahba ${ }^{1}$ \\ Juliana Bonetti Simão ${ }^{1}$ \\ ${ }^{1}$ Pontifícia Universidade Católica de São Paulo, SP, Brasil. $\quad$ 'Pontifícia Universidade Católica de São Paulo, SP, Brasil.
}

Resumo: Este estudo quantitativo visou elucidar o que homens e mulheres heterossexuais entendem por sexo sem compromisso/sexo casual. Consideraram-se motivações, atitudes e comportamentos associados a essa prática como categorias de análises representativas do fenômeno. Utilizou-se questionário de autopreenchimento, distribuído e aplicado via internet. Participaram 74 mulheres e 61 homens, entre 30 e 50 anos, escolaridade média ou superior e classe social média. Os resultados sugerem que, no sexo casual, homens e mulheres possuem em comum o desejo por encontro e prazer, confirmando que a sexualidade se imprimiu de novas modulações de subjetivação do corpo e de relacionamentos interpessoais, particularmente para a mulher. Entretanto, essas identidades e inserções sociais e afetivas subjetivam-se na forma de um duplo padrão sexual que denota de modo ainda tradicional os papéis atribuídos a cada gênero. Diferem algumas expectativas de vinculação posterior e as mulheres consideramse prejulgadas pela sociedade quando praticam sexo casual. Os homens tendem a buscar mais esse tipo de relacionamento, ao passo que as mulheres mostram maior liberdade na expressão de intimidade.

Palavras-chave: Heterossexualidade, Sexo sem Compromisso, Sexo Casual, Duplo Padrão Sexual, Gênero.

\section{Casual Sex: Motivations, Attitudes and Behaviors of Heterosexual Men and Women}

\begin{abstract}
A quantitative research was conducted to verify what heterosexual men and women understand as sex without commitment/casual sex. Motivations, attitudes and behaviors associated with this practice were considered categories of analysis representative of the phenomenon. The instrument employed was a self-completion internet questionnaire. Participants were middle class women (74) and men (61) aged between 30 and 50 years old who completed at least high school. The results suggest that in casual sex, men and women share a desire for encounter and pleasure, confirming that sexuality has been influenced by new modulations of body subjectivation and interpersonal relationships, particularly for women. However, these social and affective identities and insertions are subjectivized through a double sexual pattern that still displays traditionally the roles assigned to each gender. Some expectations of future attachment differ, and women consider themselves subjected to society prejudices when they engage in casual sex. Men tend to pursue this kind of relationship more than women, while women show greater freedom expressing intimacy.
\end{abstract}

Keywords: Heterosexuality, Sex without Commitment, Casual Sex, Sexual Double Standard, Gender. 


\title{
Sexo Casual: Motivaciones, Actitudes y Comportamientos de Hombres y Mujeres Heterosexuales Adultos
}

\begin{abstract}
Resumen: Esta investigación cuantitativa tuvo por objetivo elucidar lo que hombres y mujeres heterosexuales entienden como sexo sin compromiso/sexo casual. Se consideran las motivaciones, actitudes y comportamientos asociadas a esta práctica como categorías de análisis representativos del fenómeno. Se utilizó una encuesta de autorrelleno, distribuida y aplicada por internet. Contestaron a la encuesta 74 mujeres y 61 hombres, entre 30 y 50 años de edad, nivel de estudios secundaria o superior y clase social mediana. Los resultados sugieren que, en el sexo casual, hombres y mujeres poseen en común el deseo de encuentro y placer, confirmando que la sexualidad se imprimió de nuevas modulaciones de la subjetivación del cuerpo y de relacionamientos interpersonales, particularmente para la mujer. Todavía, esas identidades e inserciones sociales y afectivas se subjetivan en forma de un doble estándar sexual que denota de modo todavía tradicional los papeles atribuidos a cada género. Algunas expectativas sobre la vinculación posterior difieren, y las mujeres se consideran prejuzgadas por la sociedad cuando practican el sexo casual. Los hombres tienden a buscar más ese tipo de relacionamiento, mientras las mujeres muestran mayor libertad en la expresión de intimidad.
\end{abstract}

Palabras clave: Heterosexualidad, Sexo sin Compromiso, Sexo Casual, Doble Estándar Sexual, Género.

Este artigo pautou-se em uma pesquisa de Mestrado da Pontifícia Universidade Católica de São Paulo (PUC-SP) das autoras visando à compreensão do sexo sem compromisso/sexo casual em uma amostra de homens e mulheres heterossexuais adultos, brasileiros, de classe média, que responderam sobre o tema, destacando motivações, atitudes e comportamentos envolvidos. Escolheu-se trabalhar com a faixa etária de 30 a 50 anos, pois se supõe que sejam pessoas com autonomia financeira, experiência de relacionamentos e vida sexual ativa; aqueles que responderam situaram-se no estrato de classe média.

As pesquisadoras aliam sua prática clínica e observação de pacientes com queixas de insatisfação sexual e de solidão. Uma das autoras, durante o mestrado, aprimorou sua especialização na área de psicoterapia focada na sexualidade, e atualmente atende pacientes com disfunções e problemáticas sexuais, assim como promove palestras educativas sobre sexualidade. Este estudo tem como pano de fundo as mudanças históricas que modificaram a delimitação do que foi sendo historicamente atribuído ao masculino e ao feminino, dentro de uma ordem normativa do gênero, e suas implicações na expressão da sexualidade.

Estudos sobre sexualidade remontam à década de 1940: em 1948, Kinsey, um dos pioneiros nos estudos em sexologia, publicou seu primeiro relatório sobre a sexualidade masculina, e no segundo volume de seu relatório discutiu a sexualidade feminina, dando início à desconstrução dos valores americanos e da sociedade ocidental tradicionais em torno da família e da sociedade. Kinsey (1954) trouxe à tona a masturbação masculina e feminina e fantasias sexuais diversas. Após Kinsey, Master e Johnson (1984) publicaram a Resposta sexual humana, uma ampla pesquisa laboratorial com homens e mulheres que investigou também modos de orgasmo na mulher, estudo continuado por Shere Hite em 1976, sexóloga e feminista, com o Relatório Hite: um profundo estudo sobre a sexualidade feminina, uma das mais extensas pesquisas em sexualidade feminina.

O debate prosseguiu com as noções posteriores sobre gênero e, numa primeira tentativa de desnaturalizar as relações hierarquizadas entre os sexos, o termo visou incorporar o caráter cultural das distinções entre homens e mulheres e ideias sobre masculinidade e feminilidade, compreendendo que sexo está vinculado à biologia e gênero à cultura (Piscitelli, 2009; Rubin, 1986). Nessa perspectiva, na qual o gênero seria entendido como a mera expressão cultural do sexo, a sensibilidade, a afetividade e a amorosidade são atribuídas às mulheres, e a independência, 
a agressividade e a dominância aos homens, tendendo a preservar dicotomias (natureza/cultura; homem/mulher) (Nogueira, 2001). Postulando que a noção de gênero muda de acordo com as transformações históricas e sociais, Joan Scott (1986) realça que a compreensão da sexualidade não se limita ao sexo biológico. Assim, para essa autora, o gênero não é uma derivação do sexo, mas é o próprio sistema normativo que nos fez historicamente produzir a ideia da existência de dois sexos naturais em que um é hierarquicamente superior ao outro. Para Scott, as desigualdades de poder são construídas na intersecção do gênero. A partir de tais pressupostos, neste trabalho, referimo-nos a aspectos particulares a partir da díade homens e mulheres entendidos como produção cultural e, portanto, passível de questionamentos, sem conotarmos a natureza biológica de um ou outro sexo, mas focando a falácia da inferência comportamental decorrente dele como dado natural.

A noção hierarquizada de gênero foi e continua sendo contestada pelos movimentos feministas. Esses movimentos, a partir da chamada revolução sexual, construíram mudanças em busca de direitos igualitários e de simetria entre homens e mulheres (Carelli, 2013). O advento da pílula anticoncepcional em 1969 marcou o início da liberação sexual para as mulheres, uma vez que o ato sexual deixou de servir exclusivamente à procriação e possibilitou que a mulher adquirisse maior liberdade para estudar ou participar do mercado de trabalho (Del Priori, 2011). Lipovetsky (2007) destaca as mudanças na apropriação de escolhas da mulher, configurando sua identidade, entre as quais foram fundamentais as mudanças histórico-sociais, tais como: o controle da contracepção, a legitimação do trabalho assalariado feminino e a valorização das mulheres que buscam uma carreira.

Uma das práticas que marca esse novo contexto afetivo e sexual é o que se convencionou chamar de sexo sem compromisso/sexo casual, termo genérico que define relacionamentos sexuais que diferem uns dos outros por nuances desde um único encontro sexual até encontros repetitivos sem vínculo estável ou relações em que o vínculo existente é o da amizade (Wentland \& Reissing, 2014). Todavia, apesar dessas transformações, são escassos os registros que tratam o assunto do sexo sem compromisso no Brasil, em quase todas as áreas do conhecimento e, principalmente, no campo da Psicologia.

Até onde nos é dado conhecer, a prática do sexo sem compromisso, quando retratada, aparece com maior frequência em pesquisas norte-americanas com adultos jovens, tais como no estudo de Bersamin et al. (2014), que aborda o sexo casual e a saúde mental em jovens adultos, ou no de Jonason (2013), que trata das diversas práticas sexuais casuais em jovens universitários, e são escassos os relatos que envolvam pessoas com idades entre 30 e 50 anos nesses estudos fenômeno frequente na clínica, indicando novos arranjos afetivos. Faz-se necessário reforçar as pesquisas condizentes à realidade brasileira, apontando, das encontradas: o estudo de Soster e Castro (2018), que buscou entender a associação entre autoestima e prática do sexo casual em jovens universitárias entre $18 \mathrm{e}$ 25 anos; o estudo de Jota (2008), que tem por objetivo compreender em que medida a prática do sexo casual em mulheres com idade entre 20 e 30 anos suscita problemáticas subjetivas femininas específicas da atualidade; o estudo de Aquino et al. (2012), que teve por objetivo entender em que medida o amor e o "ficar" se relacionam entre si e com o sentido da vida em jovens universitários, concluindo que o "ficar" busca corporeidade e sensações momentâneas e é associado negativamente ao compromisso e à intimidade; e o estudo de Palacio (2014), que buscou compreender o relato subjetivo de mulheres jovens, entre 21 e 36 anos, que moram em repúblicas na cidade de São Paulo a respeito das relações amorosas com os homens e concluiu que o relacionamento ideal dessas mulheres modernas não adere nem ao padrão romântico e nem ao vínculo sem compromisso, permanecendo ainda em construção.

Entende-se por sexo causal encontros sexuais que ocorrem sem a necessidade de sentimentos afetivos, tais como amor e paixão, ou de intimidade, ainda que esta possa estar presente. Pode ter ou não ter continuidade de encontros. Considera-se um fenômeno fruto da revolução sexual e de movimentos feministas visando maior liberdade de escolha e de satisfação mediante uma sexualidade mais recreativa e liberal (Figueiredo, 2016; Goldenberg 2015; Navarro Lins, 2015, 2018).

Uma das modalidades é de amigos-com-beneficios, quando duas pessoas praticam o sexo casual e também mantêm alguns encontros não sexuais em um contexto social e público (Jonason et al., 2015).

De acordo com Jonason (2013), os relacionamentos com compromisso oferecem apoio emocional e "amigos-com-benefícios" seria um ensaio para um relacionamento compromissado. Já numa perspectiva patologizante, Jonason et al. (2015) referem que o apego inseguro, a psicopatia e o narcisismo estariam 
associados a relacionamentos sexuais casuais e que indivíduos com atitudes seguras no amor expressariam aversão a esse modo de relação, ao passo que aqueles com atitudes mais instáveis estabeleceriam mais frequentemente relacionamentos desse tipo. Outras pesquisas indicariam, ainda, que sexo sem compromisso/sexo casual é negativamente associado ao bem-estar e positivamente associado ao sofrimento psíquico (Bersamin et al., 2014). Essas pesquisas são norte-americanas, devendo-se entender o prisma cultural distinto no Brasil.

Quando se trata da diferença entre gêneros, a partir de uma perspectiva social e cultural, destacam-se trabalhos que encontraram variações em motivações e expectativas em torno do sexo sem compromisso. Segundo levantamento bibliográfico feito por Poeschl et al. (2003), homens e mulheres têm um repertório de comportamento praticamente igual, mas as expectativas sociais diferem em relação à maneira como cada um deve se comportar, produzindo repertórios narrativos distintos para cada gênero. Assim, a frequência de envolvimento em relações de sexo casual seria maior entre homens do que entre mulheres (Bersamin et al., 2014); segundo Jota (2008), as mulheres que praticam sexo sem compromisso preferem fazê-lo com um parceiro fixo com quem tenham intimidade, e tendem a considerar o relacionamento casual como um degrau para o estabelecimento de um vínculo mais permanente, o que é confirmado na literatura estrangeira (Goldenberg, 2014; Jonason, 2013). Tais peculiaridades poderiam advir do que se denominou de duplo padrão sexual, entendido como um conjunto de normas sociais que determinam a prática de comportamentos sexuais diferenciados para cada gênero, normas por meio das quais seria concedida aos homens uma maior liberdade sexual (Conley et al., 2012; Ramos et al., 2005; Reiss, 1964).

O duplo padrão denuncia estereótipos que endossam a ideia de que mulheres devem expressar sua sexualidade de forma mais contida que os homens e levam a sociedade a julgá-las mais severamente com relação ao seu comportamento sexual. Portanto, mulheres tenderiam a antecipar consequências negativas por aceitarem sexo sem compromisso/sexo casual. Para os homens, contrariamente, a expectativa para tal comportamento é positiva, o que explicaria, parcialmente, a maior probabilidade de homens se envolverem nesse tipo de relacionamento (Conley et al., 2012; Ramos at el., 2005).
Tais aspectos aparentemente contraditórios entre liberdade e manutenção de normas incitou a questão a ser discutida neste trabalho, que visa elucidar formas de expressão da sexualidade humana e o papel da mulher emancipada que busca usufruir os privilégios da falta de compromisso antes permitida somente aos homens.

\section{Método}

A intervenção foi feita via internet com questionário criado pelas pesquisadoras por meio do programa Google Docs. Optou-se pelo método quantitativo, com a utilização de análise estatística dos dados, de modo a ampliar o alcance dos resultados referentes a motivações, atitudes e comportamentos de homens e mulheres heterossexuais adultos sobre o sexo sem compromisso no Brasil.

Define-se "motivação" como um sentimento interno, um desejo ou um impulso que leva alguém a fazer alguma coisa (Rogers et al., 1997); "atitude" como uma "prontidão da psique para agir ou reagir de determinado modo" (Jung, 1921/1971, para. 687), e uma "maneira organizada e coerente de pensar, reagir, considerando emoção, pensamentos e crenças" (Lambert \& Lambert, 1968, p. 78); e "comportamento" como a atividade de um organismo em resposta a estímulos externos ou internos, incluindo atividades observáveis objetivamente, atividades observáveis introspectivamente e processos inconscientes (Vandenbos, 2010).

Os participantes da pesquisa foram 61 homens e 74 mulheres adultos, entre 30 e 50 anos, heterossexuais, brasileiros e residentes na região sudeste (Minas Gerais e São Paulo) do Brasil. Utilizou-se como critério de inclusão ter praticado sexo sem compromisso nos últimos cinco anos, período considerado suficiente para caracterizar um fenômeno. A pesquisa utilizou o tipo de amostra intencional por critério e selecionado em bola de neve, iniciado por meio de grupos sociais e profissionais compostos pelo círculo pessoal de uma das pesquisadoras. O convite à participação foi feito mediante mensagem explicando em que consistia a pesquisa enviada por e-mail à lista de contato da pesquisadora que levantou os dados e postagem na página do Facebook da pesquisadora com link para informações sobre a pesquisa e para o Termo de Consentimento que, depois de clicado, indicando o consentimento em participar, remetia ao questionário utilizado no levantamento de dados, respondido anonimamente.

O questionário foi dividido em três partes: a) dados de identificação; b) motivações e atitudes; e c) 
comportamentos. As questões referentes a motivações e atitudes configuraram-se em uma escala variando de 1 a 6 , na qual 1 representava discordo fortemente e 6 , concordo fortemente. As questões referentes aos comportamentos configuraram-se em uma escala de 1 a 6 , na qual 1 representava nunca e 6, sempre. O participante foi convidado a responder escolhendo na escala a pontuação que considerasse mais apropriada.

O tratamento estatístico foi realizado por meio da estatística descritiva de amostra e de técnicas de inferência estatística, e os dados foram processados mediante $o$ programa (SPSS) Statistical Package of Social Sciences. Utilizou-se a média como medida de tendência central para descrever as motivações, atitudes e comportamentos dos participantes em relação aos escores da escala. O teste tde Student foi aplicado para comparar as médias das populações das quais foram retiradas duas amostras independentes (homens e mulheres). A probabilidade de erro considerou o limite de 0,05 , em que todo $p>0,05$ indica que não existe diferença significativa entre as médias populacionais.

Juntou-se em uma categoria motivações e atitudes, pois não foram excludentes. Na análise procurou-se diferenciar ambas. Subcategorias foram estabelecidas de acordo com o método de análise de categorias de Bardin (2011). As seguintes subcategorias emergiram na categoria "Motivações e Atitudes": envolvimento; preferência e nível de satisfação; experiência afetiva; duplo padrão sexual e estímulo. E, em "Comportamentos", destacaram-se: o parceiro para sexo sem compromisso; e outros comportamentos associados ao sexo sem compromisso.

O projeto foi inscrito na Plataforma Lattes Brasil e seguiu o procedimento ético preconizado pelas resoluções no 466, de 12 de dezembro de 2012 e no 510, de 7 de abril de 2016 do Conselho Nacional de Saúde referentes às diretrizes éticas para pesquisas em Ciências Humanas e Sociais, tendo sido aprovado pelo Comitê de Ética em Pesquisa da PUC-SP sob o número de protocolo 125547/2015.

\section{Resultados}

\section{Caracterização da amostra}

Mais da metade da amostra foi constituída por mulheres (55\%). Nesse grupo predominaram aquelas com idade entre 30 e 35 anos $(55,4 \%)$ e as que residem na região sudeste $(85,1 \%)$ e na capital do estado $(70,3 \%)$. São pessoas que, em sua grande maioria, têm escolaridade de nível superior ou acima (90,55\%) e exercem uma atividade remunerada (92\%), mais frequentemente em tempo integral (59,5\%). A maior parte desse grupo é constituída por mulheres que não são mães $(75,7 \%)$ e que consideram estar em um relacionamento estável (59,5\%), cuja duração está entre um e cinco anos $(43,2 \%)$. Mais da metade das mulheres que responderam ao questionário professa a religião cristã $(58,1 \%)$. A maioria iniciou a vida sexual com um namorado (73\%) e declarou não praticar sexo sem compromisso com outras mulheres, mesmo que ocasionalmente $(87,8 \%)$.

O grupo constituído por homens representou $45 \%$ do total da amostra. De modo semelhante ao que se constata no grupo feminino, há predomínio da faixa etária que vai dos 30 aos 35 anos (54,1\%). São também indivíduos que, em sua grande maioria, residem no sudeste do país $(91,8 \%)$, embora estejam menos concentrados na capital do estado $(44,3 \%)$. Ainda como no caso das mulheres participantes da pesquisa, são mais frequentes aqueles com escolaridade de nível superior ou acima $(85,25 \%)$ e que se dedicam a uma atividade remunerada $(90,2 \%)$. Todavia, nesse caso, a frequência do trabalho em tempo integral é maior $(73,8 \%)$ do que a observada no conjunto das mulheres. A maior parte dos respondentes considerou estar em um relacionamento estável (59\%), com duração superior a cinco anos (56,7\%). Grande parte do grupo masculino não tem filhos (59\%). Mais da metade dos participantes professa a religião cristã $(65,6 \%)$. Como no grupo feminino, predominam aqueles que declaram não praticar sexo sem compromisso com pessoas do mesmo sexo (80,3\%). Todavia, diferentemente do relatado pelas mulheres, menos da metade $(47,5 \%)$ dos homens da amostra indicou ter iniciado sua vida sexual com uma namorada e, para aproximadamente $20 \%$ dos respondentes, tal iniciação se deu com uma estranha ou com uma profissional do sexo.

Considerando as características mais comuns, observa-se que a amostra foi composta, predominantemente, por adultos da região sudeste do país. São pessoas com alto nível de escolaridade e que, em geral, exercem uma atividade remunerada. A maior parte dos respondentes afirmou que tem uma orientação heterossexual, declarando não manter relações casuais com pessoas do mesmo sexo, encontrando-se em um relacionamento estável com duração entre um a cinco anos, no caso das mulheres, e superior a cinco anos, no grupo masculino. A maioria tem como religião o cristianismo, considerado em suas várias vertentes.

Apresentam-se a seguir as variáveis que mostraram uma diferença significativa na população de homens e mulheres. 


\section{Motivações e atitudes: envolvimento}

Como se vê na Tabela 1, os homens participantes da pesquisa consideraram, significativamente mais do que o grupo feminino, a distinção entre amor e sexo (média feminina (Mfeminina) $=4,01$; média masculina (Mmasculina) $=4,61 ; \mathrm{e}^{*} \mathrm{p}=0,039$ ). Nota-se, ainda, uma clara diferença entre os grupos no que se refere à duração esperada do relacionamento, com os homens, de modo mais frequente que as mulheres, buscando relacionamentos apenas passageiros quando se trata de sexo sem compromisso (Mfeminina $=3,26$; Mmasculina $=4,18 ; \mathrm{e}^{*} \mathrm{p}=0,002$ ).

As expectativas de envolvimento afetivo e de formação de vínculo parecem ser diferentes. Homens, em geral, tenderiam a não ter a atitude de buscar relacionamentos que pudessem levar à formação de vínculos (Mfeminina $=4,15 ;$ Mmasculina $=3,34 ; \mathrm{e}^{*} \mathrm{p}=0,007$ ) nem a se envolver afetivamente tanto quanto as mulheres (Mfeminina $=3,78 ;$ Mmasculina $=2,93 ; \mathrm{e}^{*} \mathrm{p}=0,002$ ).

Quanto às motivações, em resposta às questões que diziam respeito à criação de expectativas de um relacionamento comprometido a partir do sexo casual, mulheres e homens, em boa parte, declararam não criar tais expectativas, resposta essa que aparece com maior ênfase no grupo masculino (Mfeminina $=3,59$; Mmasculina $\left.=4,61 ; \mathrm{e}^{*} \mathrm{p}=0,001\right)$. O grupo feminino mostrou maior tendência que a do masculino a considerar importante que o parceiro mantivesse contato nos dias seguintes (Mfeminina $=3,69$; Mmasculina $=2,21 \mathrm{e}^{*} \mathrm{p}=0,000$ ).

Tabela 1

Subcategoria "envolvimento".

\begin{tabular}{|c|c|c|c|c|c|}
\hline \multirow{2}{*}{ Questão } & \multicolumn{3}{|c|}{ Média e Desvio Padrão } & \multirow[b]{2}{*}{$\mathrm{t}$} & \multirow{2}{*}{$\mathrm{P}$} \\
\hline & Feminino & Masculino & Total & & \\
\hline \multirow{2}{*}{ Para mim, sexo e amor são coisas distintas. } & $\mathrm{M}=4,01$ & $\mathrm{M}=4,61$ & $\mathrm{M}=4,28$ & \multirow{2}{*}{$-2,08$} & \multirow{2}{*}{$* 0,039$} \\
\hline & $\mathrm{DP}=1,756$ & $\mathrm{DP}=1,509$ & $\mathrm{DP}=1,669$ & & \\
\hline \multirow{2}{*}{$\begin{array}{l}\text { Quando faço sexo sem compromisso, busco } \\
\text { relacionamentos que sejam somente passageiros. }\end{array}$} & $M=3,26$ & $\mathrm{M}=4,18$ & $M=3,67$ & \multirow{2}{*}{$-3,122$} & \multirow{2}{*}{${ }^{*} 0,002$} \\
\hline & $\mathrm{DP}=1,729$ & $\mathrm{DP}=1,688$ & $\mathrm{DP}=1,765$ & & \\
\hline \multirow{2}{*}{$\begin{array}{l}\text { Eu me envolvo afetivamente com meu parceiro(a) } \\
\text { de sexo sem compromisso. }\end{array}$} & $\mathrm{M}=3,78$ & $\mathrm{M}=2,93$ & $\mathrm{M}=3,40$ & \multirow{2}{*}{3,226} & \multirow{2}{*}{$* 0,002$} \\
\hline & $\mathrm{DP}=1,483$ & $\mathrm{DP}=1,569$ & $\mathrm{DP}=1,575$ & & \\
\hline \multirow{2}{*}{$\begin{array}{l}\text { Quando faço sexo sem compromisso, busco } \\
\text { relacionamentos que possibilitem troca emocional } \\
\text { e formação de vínculo. }\end{array}$} & $\mathrm{M}=4,15$ & $\mathrm{M}=3,34$ & $\mathrm{M}=3,79$ & \multirow[b]{2}{*}{2,74} & \multirow[b]{2}{*}{$* 0,007$} \\
\hline & $\mathrm{DP}=1,710$ & $\mathrm{DP}=1,682$ & $\mathrm{DP}=1,738$ & & \\
\hline \multirow{2}{*}{$\begin{array}{l}\text { Quando faço sexo sem compromisso, não crio } \\
\text { expectativas de um relacionamento sério. }\end{array}$} & $\mathrm{M}=3,59$ & $\mathrm{M}=4,61$ & $\mathrm{M}=4,05$ & \multirow{2}{*}{$-3,497$} & \multirow{2}{*}{${ }^{*} 0,001$} \\
\hline & $\mathrm{DP}=1,703$ & $\mathrm{DP}=1,636$ & $\mathrm{DP}=1,742$ & & \\
\hline \multirow{2}{*}{$\begin{array}{l}\text { Quando faço sexo sem compromisso, crio } \\
\text { expectativas de um relacionamento sério. }\end{array}$} & $\mathrm{M}=2,81$ & $\mathrm{M}=2,48$ & $\mathrm{M}=2,66$ & \multirow{2}{*}{1,226} & \multirow{2}{*}{0,222} \\
\hline & $\mathrm{DP}=1,685$ & $\mathrm{DP}=1,445$ & $\mathrm{DP}=1,584$ & & \\
\hline \multirow{2}{*}{$\begin{array}{l}\text { Quando faço sexo sem compromisso com alguém, } \\
\text { é importante que ele(a) tome a iniciativa de ligar } \\
\text { ou mandar mensagem no(s) dia(s) seguinte(s). }\end{array}$} & $\mathrm{M}=3,69$ & $\mathrm{M}=2,21$ & $\mathrm{M}=3,02$ & \multirow{2}{*}{5,566} & \multirow{2}{*}{${ }^{*} 0,000$} \\
\hline & $\mathrm{DP}=1,805$ & $\mathrm{DP}=1,266$ & $\mathrm{DP}=1,743$ & & \\
\hline
\end{tabular}

No que diz respeito às atitudes, as respostas relacionadas ao modo de envolvimento levam a crer que no grupo feminino a expectativa de relacionamentos longos posteriores a esses encontros seja maior do que nos homens.

Quando comparada à amostra masculina, elas tenderiam também a se envolver afetivamente e a esperar que o parceiro tome a iniciativa de retomar o contato após o ato sexual. Em contrapartida, os homens participantes da pesquisa responderam evitar o envolvimento afetivo em relacionamentos sexuais casuais.

\section{Motivações e atitudes: preferência e nível de satisfação}

De acordo com a Tabela 2, os resultados indicam que os participantes da amostra de ambos os sexos preferem o sexo com compromisso ao sexo casual. Todavia, nota-se que as mulheres denotaram motivação maior 
para o sexo com compromisso do que os homens (Mfeminina $=5,07 ;$ Mmasculina $=4,38 ; \mathrm{e}^{*} \mathrm{p}=0,009$ ).

Ambos os grupos declararam atingir o orgasmo nas duas modalidades de prática sexual: com compromisso (Mfeminina $=5,19$; Mmasculina $=5,33$; sem diferença significativa) ou sem compromisso (Mfeminina $=4,08$; Mmasculina $=4,98$; ${ }^{*} \mathrm{p}=0000$ ), ainda que os resultados nesse quesito para sexo com compromisso sejam maiores do que para sexo sem compromisso. É digno de nota o fato de que os homens participantes da pesquisa expressaram atingir o orgasmo no sexo sem compromisso com mais frequência do que as mulheres.
Os resultados sugerem haver uma diferença na atitude de homens e mulheres em relação ao prazer que pode decorrer do ato sexual: o grupo masculino tenderia a se preocupar mais com o prazer da parceira (Mfeminina $=4,28$; Mmasculina $=5,05 ; \mathrm{e}^{*} \mathrm{p}=0,005$ ), ao passo que as mulheres estariam mais concentradas na busca do seu próprio prazer (Mfeminina $=5,08$; Mmasculina = 4,57; $\mathrm{e}^{*} \mathrm{p}=0,027$ ).

Tem-se, ainda, que os homens apresentaram uma tendência mais acentuada de considerar o sexo sem compromisso uma boa experiência $\left(\right.$ Mmasculina $=4,38 ;$ Mfeminina $\left.=3,81 ; \mathrm{e}^{*} \mathrm{p}=0,023\right)$.

Tabela 2

Subcategoria "Preferência e nível de satisfação".

\begin{tabular}{|c|c|c|c|c|c|}
\hline \multirow{2}{*}{ Questão } & \multicolumn{3}{|c|}{ Média e Desvio Padrão } & & \multirow{2}{*}{$\mathrm{P}$} \\
\hline & Feminino & Masculino & Total & & \\
\hline \multirow{2}{*}{$\begin{array}{l}\text { Prefiro o sexo sem compromisso ao sexo com } \\
\text { compromisso (sexo em um relacionamento } \\
\text { estável). }\end{array}$} & $\mathrm{M}=1,89$ & $M=2,38$ & $M=2,11$ & \multirow{2}{*}{$-1,875$} & \multirow{2}{*}{0,063} \\
\hline & $\mathrm{DP}=1,277$ & $\mathrm{DP}=1,655$ & $\mathrm{DP}=1,474$ & & \\
\hline \multirow{2}{*}{$\begin{array}{l}\text { Prefiro o sexo com compromisso } \\
\text { (sexo em um relacionamento estável) } \\
\text { ao sexo sem compromisso. }\end{array}$} & $\mathrm{M}=5,07$ & $\mathrm{M}=4,38$ & $\mathrm{M}=4,76$ & \multirow{2}{*}{2,641} & \multirow{2}{*}{$*_{0}^{*} 0,00 \varsigma$} \\
\hline & $\mathrm{DP}=1,317$ & $\mathrm{DP}=1,655$ & $\mathrm{DP}=1,513$ & & \\
\hline \multirow{2}{*}{$\begin{array}{l}\text { O sexo com compromisso (sexo em um } \\
\text { relacionamento estável) me leva ao orgasmo. }\end{array}$} & $\mathrm{M}=5,19$ & $\mathrm{M}=5,33$ & $\mathrm{M}=5,25$ & \multirow{2}{*}{$-0,659$} & \multirow{2}{*}{0,511} \\
\hline & $\mathrm{DP}=1,201$ & $\mathrm{DP}=1,235$ & $\mathrm{DP}=1,214$ & & \\
\hline \multirow{2}{*}{ O sexo sem compromisso me leva ao orgasmo. } & $\mathrm{M}=4,08$ & $\mathrm{M}=4,98$ & $\mathrm{M}=4,49$ & \multirow{2}{*}{$-3,637$} & \multirow{2}{*}{${ }^{*} 0,000$} \\
\hline & $\mathrm{DP}=1,586$ & $\mathrm{DP}=1,297$ & $\mathrm{DP}=1,525$ & & \\
\hline \multirow{2}{*}{$\begin{array}{l}\text { Quando faço sexo sem compromisso com } \\
\text { alguém, eu me preocupo com o prazer do meu } \\
\text { parceiro(a). }\end{array}$} & $\mathrm{M}=4,28$ & $M=5,05$ & $\mathrm{M}=4,63$ & \multirow{2}{*}{$-2,854$} & \multirow{2}{*}{$* 0,005$} \\
\hline & $\mathrm{DP}=1,583$ & $\mathrm{DP}=1,510$ & $\mathrm{DP}=1,592$ & & \\
\hline \multirow{2}{*}{$\begin{array}{l}\text { Quando faço sexo sem compromisso com } \\
\text { alguém, eu me preocupo com o meu prazer. }\end{array}$} & $\mathrm{M}=5,08$ & $\mathrm{M}=4,57$ & $\mathrm{M}=4,85$ & \multirow{2}{*}{2,24} & \multirow{2}{*}{${ }^{*} 0,027$} \\
\hline & $\mathrm{DP}=1,214$ & $\mathrm{DP}=1,384$ & $\mathrm{DP}=1,313$ & & \\
\hline \multirow{2}{*}{$\begin{array}{l}\text { A relação sexual sem compromisso para mim é } \\
\text { uma boa experiência. }\end{array}$} & $\mathrm{M}=3,81$ & $\mathrm{M}=4,38$ & $\mathrm{M}=4,07$ & \multirow{2}{*}{$-2,306$} & \multirow{2}{*}{${ }^{*} 0,023$} \\
\hline & $\mathrm{DP}=1,661$ & $\mathrm{DP}=1,186$ & $\mathrm{DP}=1,487$ & & \\
\hline \multirow{2}{*}{$\begin{array}{l}\text { Após a prática do sexo sem compromisso, sinto } \\
\text { ansiedade e inquietação. }\end{array}$} & $\mathrm{M}=3,31$ & $\mathrm{M}=3,07$ & $\mathrm{M}=3,20$ & \multirow{2}{*}{0,778} & \multirow{2}{*}{0,438} \\
\hline & $\mathrm{DP}=1,879$ & $\mathrm{DP}=1,750$ & $\mathrm{DP}=1,819$ & & \\
\hline \multirow{2}{*}{$\begin{array}{l}\text { Após a prática do sexo sem compromisso, sinto } \\
\text { bem-estar. }\end{array}$} & $\mathrm{M}=3,49$ & $\mathrm{M}=3,90$ & $\mathrm{M}=3,67$ & \multirow{2}{*}{$-1,636$} & \multirow{2}{*}{0,104} \\
\hline & $\mathrm{DP}=1,598$ & $\mathrm{DP}=1,350$ & $\mathrm{DP}=1,500$ & & \\
\hline
\end{tabular}

Em seu conjunto, as respostas relativas a preferências e nível de satisfação indicaram que, ainda que a maioria dos participantes declare privilegiar a prática do sexo com compromisso e ali encontrar satisfação sexual, o sexo sem compromisso é também considerado, por grande parte da amostra, como fonte de prazer e uma boa experiência. As diferenças encontradas entre o grupo masculino e o feminino referem-se, principalmente, à preocupação que eles demonstram com o prazer da parceira, ao passo que as mulheres tenderiam a focalizar mais o próprio prazer.

\section{Motivações e atitudes: experiência afetiva}

Conforme a Tabela 3, os dados encontrados indicam que experiências afetivas com o sexo oposto - que envolvem atitudes e motivações para 
buscar e ir ao encontro do outro -, consideradas de modo amplo (não necessariamente sexual), são vistas como melhores do que as entre iguais. Parece ser digno de nota, todavia, a frequência com que os homens participantes da pesquisa declararam não ter uma boa relação afetiva com outros homens (Mmasculina $=2,46)$, ao passo que consideraram, em sua maioria, estabelecer bons relacionamentos com mulheres (Mmasculina $=5,11$ ). As mulheres tenderiam a ter uma boa relação afetiva com o sexo oposto (Mfeminina $=5,26$ ) e, comparativamente ao grupo masculino, apenas uma parte indica não terem uma boa relação afetiva com outras mulheres (Mfeminina $=3,82)\left({ }^{*} \mathrm{p}=0,000\right)$.

Tabela 3

Subcategoria “Experiência afetiva”.

\begin{tabular}{|c|c|c|c|c|c|}
\hline \multirow{2}{*}{ Questão } & \multicolumn{3}{|c|}{ Média e Desvio Padrão } & \multirow[b]{2}{*}{$\mathrm{t}$} & \multirow{2}{*}{$\mathrm{P}$} \\
\hline & Feminino & Masculino & Total & & \\
\hline \multirow{2}{*}{$\begin{array}{l}\text { Eu tenho uma boa experiência afetiva com pessoas } \\
\text { do sexo feminino em geral. }\end{array}$} & $M=3,82$ & $M=5,11$ & $\mathrm{M}=4,41$ & \multirow{2}{*}{$-4,374$} & \multirow{2}{*}{${ }^{*} 0,000$} \\
\hline & $\mathrm{DP}=2,002$ & $\mathrm{M}=1,415$ & $\mathrm{DP}=1,870$ & & \\
\hline \multirow{2}{*}{$\begin{array}{l}\text { Eu tenho uma boa experiência afetiva com pessoas } \\
\text { do sexo masculino em geral. }\end{array}$} & $M=5,26$ & $\mathrm{M}=2,46$ & $\mathrm{M}=3,99$ & \multirow{2}{*}{10,956} & \multirow{2}{*}{$* 0,000$} \\
\hline & $\mathrm{DP}=0,980$ & $\mathrm{DP}=1,785$ & $\mathrm{DP}=1,976$ & & \\
\hline
\end{tabular}

\section{Motivações e atitudes: duplo padrão sexual}

Os dados constantes da Tabela 4 mostram que os resultados apresentados revelaram que os participantes consideram que a sociedade tem atitudes distintas para com homens e mulheres em relação ao sexo sem compromisso. Assim, homens e mulheres discordam que a sociedade valoriza a mulher que faz sexo sem compromisso; elas, no entanto, discordam com mais intensidade (Mfeminina $=1,70$; Mmasculina $=2,15$; e $\left.\mathrm{p}={ }^{*} 0,037\right)$. As mulheres parecem acreditar mais fortemente que a sociedade valoriza o homem que faz sexo sem compromisso, e apenas parte do grupo masculino concorda com isso (Mfeminina $=4,43$; Mmasculina $=3,46$; e p $={ }^{*} 0,001$ ). Quando a questão foi feita novamente no sentido inverso, utilizando o termo "desvalorizar", constatou-se que homens e mulheres discordaram que homens são desvalorizados pela sociedade pela prática, mas as mulheres discordaram significativamente mais que eles com essa afirmação (Mfeminina = 1,66; Mmasculina = 2,52; e $\left.\mathrm{p}={ }^{*} 0,000\right)$. Assim, as mulheres tendem, mais do que o próprio grupo masculino, a considerar que o exercício do sexo sem compromisso confere prestígio aos homens, mas eles não confirmam essa percepção quando falam de si.

As respostas às questões relacionadas à posição da sociedade em relação a homens e mulheres que praticam o sexo sem compromisso levam a supor que os participantes desta pesquisa identificam a presença de um duplo padrão sexual socialmente estabelecido, ou seja, maior valorização social para os homens e maior desvalorização social para mulheres.

Tabela 4

Subcategoria "Duplo padrão sexual".

\begin{tabular}{|c|c|c|c|c|c|}
\hline \multirow{2}{*}{ Questão } & \multicolumn{3}{|c|}{ Média e Desvio Padrão } & \multirow{2}{*}{$\mathrm{t}$} & \multirow{2}{*}{$\mathrm{P}$} \\
\hline & Feminino & Masculino & Total & & \\
\hline \multirow{2}{*}{$\begin{array}{l}\text { Considero que a sociedade valoriza a mulher } \\
\text { que faz sexo sem compromisso. }\end{array}$} & $\mathrm{M}=1,70$ & $M=2,15$ & $M=1,90$ & \multirow{2}{*}{$-2,102$} & \multirow{2}{*}{$* 0,037$} \\
\hline & $\mathrm{DP}=1,155$ & $\mathrm{DP}=1,302$ & $\mathrm{DP}=1,239$ & & \\
\hline \multirow{2}{*}{$\begin{array}{l}\text { Considero que a sociedade valoriza o } \\
\text { homem que faz sexo sem compromisso. }\end{array}$} & $\mathrm{M}=4,43$ & $\mathrm{M}=3,46$ & $\mathrm{M}=3,99$ & \multirow{2}{*}{3,369} & \multirow{2}{*}{$* 0,001$} \\
\hline & $\mathrm{DP}=1,737$ & $\mathrm{DP}=1,587$ & $\mathrm{DP}=1,734$ & & \\
\hline \multirow{2}{*}{$\begin{array}{l}\text { Considero que a sociedade desvaloriza a } \\
\text { mulher que faz sexo sem compromisso. }\end{array}$} & $\mathrm{M}=4,91$ & $\mathrm{M}=4,48$ & $\mathrm{M}=4,71$ & \multirow{2}{*}{1,58} & \multirow{2}{*}{0,117} \\
\hline & $\mathrm{DP}=1,598$ & $\mathrm{DP}=1,545$ & $\mathrm{DP}=1,583$ & & \\
\hline \multirow{2}{*}{$\begin{array}{l}\text { Considero que a sociedade desvaloriza o } \\
\text { homem que faz sexo sem compromisso. }\end{array}$} & $\mathrm{M}=1,66$ & $\mathrm{M}=2,52$ & $\mathrm{M}=2,05$ & \multirow{2}{*}{$-3,827$} & \multirow{2}{*}{$* 0,000$} \\
\hline & $\mathrm{DP}=1,089$ & $\mathrm{DP}=1,456$ & $\mathrm{DP}=1,334$ & & \\
\hline
\end{tabular}




\section{Motivações e atitudes: estímulo}

Como se vê na Tabela 5, os resultados obtidos, no que se refere a se sentir sozinho e buscar novas experiências como estímulos para a prática do sexo sem compromisso, mostraram que os participantes da pesquisa buscam o sexo sem compromisso por ambos os motivos.
Essa hipótese, todavia, deve ser vista com cautela, uma vez que a análise estatística não mostrou resultado conclusivo. Com relação à percepção de se sentir valorizado como motivação para o sexo casual, não há indícios para tanto, quer para homens, quer para mulheres (Mfeminina =1,95; Mmasculina =2,46; e p = 0,033).

\section{Tabela 5}

Subcategoria "Estímulo".

\begin{tabular}{|c|c|c|c|c|c|}
\hline \multirow{2}{*}{ Questão } & \multicolumn{3}{|c|}{ Média e Desvio Padrão } & \multirow{2}{*}{$\mathrm{t}$} & \multirow{2}{*}{$\mathrm{P}$} \\
\hline & Feminino & Masculino & Total & & \\
\hline \multirow{2}{*}{$\begin{array}{l}\text { Geralmente, busco sexo sem compromisso } \\
\text { quando me sinto sozinho(a). }\end{array}$} & $\mathrm{M}=3,43$ & $\mathrm{M}=3,48$ & $M=3,45$ & \multirow{2}{*}{$-0,141$} & \multirow{2}{*}{0,888} \\
\hline & $\mathrm{DP}=1,681$ & $\mathrm{DP}=1,849$ & $\mathrm{DP}=1,752$ & & \\
\hline \multirow{2}{*}{$\begin{array}{l}\text { Faço sexo sem compromisso porque busco } \\
\text { novas experiências. }\end{array}$} & $\mathrm{M}=3,68$ & $\mathrm{M}=4,18$ & $\mathrm{M}=3,90$ & \multirow{2}{*}{$-1,648$} & \multirow{2}{*}{0,102} \\
\hline & $\mathrm{DP}=1,873$ & $\mathrm{DP}=1,638$ & $\mathrm{DP}=1,782$ & & \\
\hline \multirow{2}{*}{ Faço sexo sem compromisso porque me valoriza. } & $\mathrm{M}=1,95$ & $M=2,46$ & $M=2,18$ & \multirow{2}{*}{$-2,151$} & \multirow{2}{*}{${ }^{*} 0,033$} \\
\hline & $\mathrm{DP}=1,333$ & $\mathrm{DP}=1,433$ & $\mathrm{DP}=1,398$ & & \\
\hline
\end{tabular}

\section{Comportamentos: o parceiro para o sexo sem compromisso}

De acordo com a Tabela 6, no que diz respeito ao parceiro(a) para sexo sem compromisso, as categorias "amigos" e "pessoas que lhes foram apresentadas por amigos em comum” não surgiram como uma possibilidade de escolha. Os homens da amostra expressaram tendência significativamente maior do que a das mulheres a fazerem sexo sem compromisso com alguém que tenham conhecido na mesma noite $\left(\right.$ Mfeminina $=2,77 ;$ Mmasculina $\left.=3,77 ; \mathrm{e}^{*} \mathrm{p}=0,001\right)$ e a praticar sexo casual com diferentes parceiras (Mfeminina =2,59; Mmasculina $=3,77 ; \mathrm{e}^{*} \mathrm{p}=0,000$ ).
Com relação ao local em que se busca o parceiro para o sexo casual, tanto os homens como as mulheres da pesquisa tendem a não escolher pessoas conhecidas por meio de aplicativos de relacionamento. Ainda assim, o grupo masculino se mostra mais propenso que o feminino a praticar sexo sem compromisso com pessoas conhecidas por meio de aplicativos da internet (Mfeminina $=1,93$; Mmasculina $=2,87$; e ${ }^{*} \mathrm{p}=0,002$ ). Igualmente, há no grupo masculino, mais do que no feminino, a inclinação para se envolver em uma relação sexual sem compromisso com pessoas que tenham sido conhecidas em bares e baladas (Mfeminina $=2,55 ;$ Mmasculina $=3,39 ; \mathrm{e}^{*} \mathrm{p}=0,005$ ).

Tabela 6

Subcategoria "Parceiro para sexo sem compromisso".

\begin{tabular}{|c|c|c|c|c|c|}
\hline \multirow{2}{*}{ Questão } & \multicolumn{3}{|c|}{ Média e Desvio Padrão } & \multirow{2}{*}{$\mathrm{t}$} & \multirow{2}{*}{$\mathrm{P}$} \\
\hline & Feminino & Masculino & Total & & \\
\hline \multirow{2}{*}{ Faço sexo sem compromisso com um amigo(a). } & $\mathrm{M}=2,62$ & $\mathrm{M}=3,13$ & $\mathrm{M}=2,85$ & \multirow{2}{*}{$-1,869$} & \multirow{2}{*}{0,064} \\
\hline & $\mathrm{DP}=1,576$ & $\mathrm{DP}=1,576$ & $\mathrm{DP}=1,591$ & & \\
\hline \multirow{2}{*}{$\begin{array}{l}\text { Faço sexo sem compromisso com pessoas que conheci } \\
\text { em aplicativos de relacionamentos na internet. }\end{array}$} & $\mathrm{M}=1,93$ & $M=2,87$ & $M=2,36$ & \multirow{2}{*}{$-3,116$} & \multirow{2}{*}{${ }^{*} 0,002$} \\
\hline & $\mathrm{DP}=1,529$ & $\mathrm{DP}=1,893$ & $\mathrm{DP}=1,760$ & & \\
\hline \multirow{2}{*}{$\begin{array}{l}\text { Faço sexo sem compromisso com pessoas que me } \\
\text { foram apresentadas por amigos em comum. }\end{array}$} & $\mathrm{M}=3,27$ & $\mathrm{M}=3,52$ & $\mathrm{M}=3,39$ & \multirow{2}{*}{$-0,928$} & \multirow{2}{*}{0,355} \\
\hline & $\mathrm{DP}=1,582$ & $\mathrm{DP}=1,588$ & $\mathrm{DP}=1,583$ & & \\
\hline \multirow{2}{*}{$\begin{array}{l}\text { Faço sexo sem compromisso com pessoas que conheci } \\
\text { em bares e baladas que frequento. }\end{array}$} & $\mathrm{M}=2,55$ & $\mathrm{M}=3,39$ & $\mathrm{M}=2,93$ & \multirow{2}{*}{$-2,831$} & \multirow{2}{*}{${ }^{*} 0,005$} \\
\hline & $\mathrm{DP}=1,631$ & $\mathrm{DP}=1,810$ & $\mathrm{DP}=1,759$ & & \\
\hline
\end{tabular}


...continuação

\begin{tabular}{|c|c|c|c|c|c|}
\hline \multirow{2}{*}{ Questão } & \multicolumn{3}{|c|}{ Média e Desvio Padrão } & \multirow{2}{*}{$\mathrm{t}$} & \multirow{2}{*}{$\mathrm{P}$} \\
\hline & Feminino & Masculino & Total & & \\
\hline \multirow{2}{*}{$\begin{array}{l}\text { Faço sexo sem compromisso com alguém que conheci } \\
\text { na mesma noite. }\end{array}$} & $\mathrm{M}=2,77$ & $\mathrm{M}=3,77$ & $\mathrm{M}=3,22$ & \multirow{2}{*}{$-3,352$} & \multirow{2}{*}{${ }^{*} 0,001$} \\
\hline & $\mathrm{DP}=1,732$ & $\mathrm{DP}=1,717$ & $\mathrm{DP}=1,790$ & & \\
\hline \multirow{2}{*}{$\begin{array}{l}\text { Pratico sexo sem compromisso com diferentes } \\
\text { parceiros(as). }\end{array}$} & $M=2,59$ & $\mathrm{M}=3,77$ & $\mathrm{M}=3,13$ & \multirow{2}{*}{$-3,918$} & \multirow{2}{*}{${ }^{*} 0,000$} \\
\hline & $\mathrm{DP}=1,687$ & $\mathrm{DP}=1,793$ & $\mathrm{DP}=1,826$ & & \\
\hline
\end{tabular}

Com respeito à preferência de parceiros, não foi possível identificar um parceiro preferencial para o grupo feminino. Os homens, por sua vez, parecem ter uma maior disponibilidade para identificar parceiras para sexo sem compromisso em ambientes mais variados.

\section{Comportamentos: outros comportamentos associados ao sexo sem compromisso}

Como se vê na Tabela 7, comparando os resultados relativos à questão "Quando faço sexo sem compromisso com alguém, é importante que ele(a) tome a iniciativa de ligar ou mandar mensagem no(s) dia(s) seguinte(s)" (vide valores da Tabela 1) com os resultados da questão "Quando faço sexo sem compromisso com alguém, eu tomo a iniciativa de ligar ou mandar mensagem no(s) dia(s) seguinte(s)", observa-se que os homens da amostra demonstrariam, mais do que as mulheres, tomar a iniciativa de manter contato com a parceira nos dias que se seguem ao encontro sexual (Mfeminina $=2,66$; Mmasculina $=3,38 ; \mathrm{e}^{*} \mathrm{p}=0,009$ ). Elas, em contrapartida, teriam mais expectativas de serem contatadas após o encontro.

Tabela 7

Subcategoria "Outros comportamentos associados ao sexo sem compromisso".

\begin{tabular}{|c|c|c|c|c|c|}
\hline \multirow{2}{*}{ Questão } & \multicolumn{3}{|c|}{ Média e Desvio Padrão } & \multirow{2}{*}{$\mathrm{T}$} & \multirow{2}{*}{$\mathrm{P}$} \\
\hline & Feminino & Masculino & Total & & \\
\hline \multirow{2}{*}{$\begin{array}{l}\text { Quando faço sexo sem compromisso com } \\
\text { alguém, eu tomo a iniciativa de ligar ou } \\
\text { mandar mensagem no(s) dia(s) seguinte(s). }\end{array}$} & $\mathrm{M}=2,66$ & $\mathrm{M}=3,38$ & $\mathrm{M}=2,99$ & \multirow[b]{2}{*}{$-2,658$} & \multirow[b]{2}{*}{$* 0,009$} \\
\hline & $\mathrm{DP}=1,337$ & $\mathrm{DP}=1,714$ & $\mathrm{DP}=1,555$ & & \\
\hline \multirow{2}{*}{$\begin{array}{l}\text { Eu uso preservativo quando faço sexo } \\
\text { sem compromisso. }\end{array}$} & $\mathrm{M}=5,14$ & $M=5,25$ & $\mathrm{M}=5,19$ & \multirow{2}{*}{$-0,498$} & \multirow{2}{*}{0,619} \\
\hline & $\mathrm{DP}=1,286$ & $\mathrm{DP}=1,287$ & $\mathrm{DP}=1,282$ & & \\
\hline \multirow{2}{*}{$\begin{array}{l}\text { Conto para amigos(as) como foi o encontro de } \\
\text { sexo sem compromisso. }\end{array}$} & $\mathrm{M}=3,42$ & $\mathrm{M}=2,74$ & $\mathrm{M}=3,11$ & \multirow{2}{*}{2,244} & \multirow{2}{*}{${ }^{*} 0,026$} \\
\hline & $\mathrm{DP}=1,712$ & $\mathrm{DP}=1,806$ & $\mathrm{DP}=1,782$ & & \\
\hline
\end{tabular}

Pode-se supor que as tendências identificadas sejam congruentes com uma visão do homem como elemento mais ativo no encontro sexual, visão essa que faz parte do duplo padrão sexual presente na sociedade. Há no grupo masculino, assim como no feminino, forte tendência a considerar importante o uso de preservativos quando em situação de sexo sem compromisso. E, por fim, observou-se que as mulheres expressaram contar para amigos(as) como foi o encontro de sexo sem compromisso significativamente mais do que homens.

\section{Discussão}

Os resultados obtidos sugerem que, ainda que sejam privilegiadas as relações sexuais vividas no contexto de um relacionamento estável, em que se estabelecem compromissos mútuos, nos dias atuais, o exercício do sexo sem compromisso é uma prática tanto para homens como para mulheres heterossexuais, quando consideramos indivíduos adultos, predominantemente urbanos, com alto nível de escolaridade e engajados em uma ocupação remunerada. Ainda que o prazer pareça estar mais presente no sexo com compromisso, o sexo casual, para ambos os gêneros, também se mostra significativamente prazeroso. No entanto, sob alguns aspectos, tal prática tende a ser vivida de forma diferente por homens e mulheres.

Aparentemente, na amostra estudada, homens e mulheres vivenciam o sexo sem compromisso 
independentemente de expectativas de vínculo amoroso e relacionamento mais estável. Cabe ressaltar, a partir das respostas, que a vivência afetiva pode se dar no contexto de sexo casual, particularmente para a mulher, que se permite experimentar o afeto em uma relação sem compromisso. Há, entretanto, expectativas distintas nas motivações e atitudes de ambos os grupos: as mulheres admitem eventual formação de vínculo posterior, ao passo que os homens referem buscar o sexo mais episódico. Independentemente de expectativas de um relacionamento estável, com compromissos mútuos, determinados e estabelecidos, o sexo sem compromisso pode ter uma gama muito ampla de afetividade envolvida. Ocorre desde o prazer sensorial momentâneo até vínculos com componentes afetivos emocionais mais duradouros, demolindo o estereótipo de que o sexo casual/sem compromisso se limite necessariamente à experiência de sensações corporais genitalizadas.

Esse dado é, em parte, congruente com os achados da pesquisa qualitativa de Jota (2008). Nesse estudo, o autor concluiu que mesmo as mulheres que fazem sexo sem compromisso preferem fazê-lo com um parceiro fixo com quem tenham intimidade e com quem, a partir disso, talvez possam oficializar um vínculo. De modo semelhante, o estudo de Jonason et al. (2013) revelou que as mulheres seriam mais propensas a almejar uma relação estável e estariam interessadas no sexo sem compromisso como uma forma de transição para um relacionamento mais estável. Nesta pesquisa verificou-se que as expectativas das mulheres incluem desejos e projetos distintos, que incluem relacionamento duradouro, menos declarados ou quase não presentes nos homens.

Este estudo também denota a existência de atitudes diferentes entre os gêneros - o fato de os homens da amostra demonstrarem, mais do que o grupo feminino, tomar a iniciativa de manter contato com a parceira nos dias que se seguem ao encontro sexual e de as mulheres, em contrapartida, demonstrarem mais expectativas de serem contatadas após o encontro.

Mais frequentemente do que as mulheres, os homens declararam atingir o orgasmo no sexo casual e considerar esse tipo de relação uma boa experiência. Apesar de relacionados, pode-se distinguir prazer de orgasmo, pelo qual o prazer seria o gatilho para despertar o orgasmo, proporcionando o envolvimento sensual de agrado presente no desejo e na excitação, e o orgasmo seria a resolução da tensão sexual
(Master \& Johnson, 1984). Pondera-se se, na atualidade, uma mudança cultural para a mulher que, da repressão do orgasmo, se viu na obrigação de atingi-lo.

O Dr. Gerson Lopes, em entrevista, declara que toda relação deve ser prazerosa, mas não necessariamente orgástica. Haveria uma espécie de ditadura do orgasmo, a "orgasmocracia", em que o "fim da festa" ganha mais atenção que a experiência sexual como um todo (Reis, 2010).

Participantes de ambos os sexos indicaram atingir o orgasmo nas duas situações - sem e com compromisso. Sob esse aspecto, o atual estudo não confirma os achados de Goldenberg (2014), que sugerem que a mulher não tem tanto prazer no sexo sem compromisso e é menos propensa a atingir o clímax nessas situações. Segundo esse autor, uma das possíveis explicações seria que homens preocupam-se menos em satisfazer os desejos delas quando o sexo é casual, e que as mulheres teriam maior dificuldade e insegurança para expor suas vontades. Este estudo também revela dados que parecem contradizer tais justificativas, uma vez que os resultados obtidos indicam que as mulheres parecem visar mais o próprio prazer, e eles, o prazer delas. Sob uma perspectiva psicodinâmica, é possível atribuir tal atitude a um valor da cultura patriarcal que faria crer que o homem potente é aquele que faz a mulher gozar. Por meio do clímax da parceira, eles obteriam uma validação narcísica da própria potência. De outro lado, ao depositarem sua virilidade no gozo delas, podem deixar de se apropriar da experiência de sensualidade e do reconhecimento do próprio corpo.

Segundo Jung (1928/2011), nesse caso, estariam em curso projeções de aspectos relacionados a uma imagem interior da anima, a qual está vinculada a conteúdos inconscientes da psique do homem que se contrapõem à identidade de gênero masculina.

Outro ponto a ponderar é que as mulheres, nesta pesquisa, demonstraram maior liberdade do que os homens na vivência dos sentimentos, não se esquivando de estabelecer uma relação de intimidade, mesmo quando em uma situação de sexo sem compromisso. Abre-se a questão sobre se os homens estariam sofrendo de uma restrição da cultura patriarcal de expressão de intimidade e sensualidade, o que constituiria a ferida patriarcal do homem (Wahba, 2016). O homem não se permitiria a vivência de uma intimidade fluida, bem como não se permite expressar afeto por pessoas do mesmo gênero, o que mostraria que a 
prevalência de valores da cultura patriarcal ainda presentes prejudica tanto homens como mulheres.

A alta frequência com que os homens participantes da pesquisa declararam não ter uma boa relação afetiva com outros homens, ao passo que consideraram, em sua maioria, estabelecer bons relacionamentos afetivos com mulheres, é uma resposta que precisa ser mais bem compreendida e explorada. Levanta-se a hipótese de que nestes homens identificados como heterossexuais haja receio de manifestar afetos em relação a outros homens, um tabu machista.

Destaca-se, ainda, que a relação inferida pelos autores Jonason et al. (2015) entre sexo casual e narcisismo e outros estados patológicos não parece ser corroborada pelos resultados desta pesquisa. Ainda que não tenha sido aplicado nenhum instrumento que avalie a personalidade, as respostas indicam pessoas com capacidade de relacionamentos afetivos e formação de vínculos dentro do que se pode considerar razoavelmente ajustado.

Com relação aos parceiros para o sexo sem compromisso, ressalta-se que, neste estudo, não foi possível identificar uma escolha preferencial para o grupo feminino. É possível que esse resultado esteja relacionado às opções oferecidas pelo questionário. Sugere-se que, em futuras pesquisas sobre o tema, a opção "colegas de trabalho" venha a ser considerada.

Observa-se, também, alta frequência nos dois grupos de respostas sobre o uso de preservativo durante $\mathrm{o}$ ato, o que pode indicar, ao contrário do que se apregoa, que não apenas as mulheres sabem negociar o uso da camisinha, como também não há resistência dos homens em usá-la. De um lado, trata-se de uma população tida como mais esclarecida e madura, mas há de se considerar se a resposta não obedeceu a uma incorporação do que deve ser, do consenso social. Haja vista que nos consultórios o número de homens de alto grau de escolaridade e formação que admitem não usar preservativo é ainda frequente, assim como de mulheres que não o solicitam.

Contrariando o que habitualmente se pensa, o comportamento "contar para amigos(as) como foi o encontro de sexo sem compromisso", reconhecido socialmente como mais prevalente entre os homens, foi mais frequente no grupo feminino. Esse dado contraria a conclusão de Bersamin et al. (2014) de que os homens seriam os mais propensos a relatar um encontro sexual casual. As mulheres entre elas parecem ter adquirido a liberdade e espontaneidade de relatos íntimos antes proibidos envolvendo o corpo, o que se comprova nos estudos sociais sobre sororidade e coletivos femininos (Barreto Lima, 2018; Tinoco, 2016).

Destaca-se, como previsto na literatura, a presença de um duplo padrão sexual (Conley et al., 2012; Figueiredo, 2016; Goldenberg, 2015; Navarro Lins, 2015, 2018; Piscitelli, 2009; Ramos et al., 2005; Reiss, 1964; Rubin, 1986; Scott, 1986) como hipótese para algumas das diferenças nas respostas dos dois grupos. As marcas dopatriarcado sexistanão desapareceram porcompleto, ainda que um movimento renovador esteja agindo, o que se revela na permissividade das mulheres experimentarem prazer e orgasmo em relações casuais.

\section{Considerações finais}

Os resultados levantados da pesquisa relatada evidenciam adultos heterossexuais que sinalizam uma mudança nas relações de gênero favorável à livre expressão de uma sexualidade que imprime novas modulações à subjetivação do corpo e aos relacionamentos interpessoais, particularmente para a mulher. A mulher atual, urbana e de elevado nível de escolaridade tenderia a assumir seu desejo e a buscar novas experiências sexuais, nas quais, assim como os homens, encontraria prazer. Neste sentido, reconhece-se a contribuição social do movimento feminista, no sentido de diminuir preconceitos e desconstruir estereótipos.

Decerto promissor, entretanto, foi também verificado que persistem registros e determinantes da cultura patriarcal que diferencia em categorias aquilo que seja próprio e característico do homem e da mulher, o que leva a distribuir deveres e direitos de modo pré-estabelecido. Em decorrência, subjetivam-se identidades e inserções sociais e afetivas na forma de um duplo padrão sexual que denota modos ainda tradicionais para os papéis atribuídos a cada gênero.

A mulher ainda se ressente por se sentir julgada e censurada por um padrão social segundo o qual, à mulher caberia adotar um comportamento sexual mais contido e menos livre. O homem, nas mesmas condições socioculturais, continua usufruindo de uma permissividade que historicamente lhe foi dada. Portanto, expectativas de relacionamentos duradouros ou momentâneos sofreriam essa influência de autorização, o que contribuiria para que o grau de satisfação com a experiência de sexo casual seja mais acentuado para eles. 
Homens e mulheres atuais parecem, de um lado, adaptados a um novo contexto sociocultural, mas, de outro, ainda estão buscando ajustar seus anseios. Apesar dos resquícios patriarcais ainda repressores sob novas formas, posto que haja maior liberdade, mas com a persistência de julgamentos pré-concebidos -, as mulheres demonstraram no estudo uma nova forma de liberdade e de quebra de preconceitos ao se permitem escolher parceiros passageiros para o prazer e, ao mesmo tempo, não negar um desejo de maior vinculação. A pergunta que se coloca é se esse anseio deveria ser interpretado como uma persistência do ideal de amor romântico ou como uma abertura. Parece-nos uma abertura de experimentar, e a este respeito, o homem se mostrou menos livre, pois a intimidade lhe é negada, a intimidade com a parceira ocasional e a intimidade afetiva com outros homens.

Uma vez que este foi um estudo de caráter quantitativo e exploratório, essa e outras questões mereceriam ser aprofundadas em novos trabalhos sobre 0 tema, a fim de compreender como homens e mulheres se apropriam da experiência dos sentimentos, da intimidade e da sensualidade. Para tanto, sugerem-se futuras pesquisas com entrevistas e, eventualmente, o uso de técnicas projetivas e grupos focais. Outra possibilidade de ampliação do campo de pesquisa seria investigar distintos segmentos socioeconômicos, discriminando estado civil, situação familiar e diversidade de gênero, dentre outras variáveis.

A pesquisa demonstrou a importância de explorar comportamentos, desempenho de papéis, expectativas e motivações na busca de relacionamentos afetivos e sexuais da atualidade, respondendo às mudanças socioculturais que afetam os indivíduos e suas relações. Mostrou, principalmente, os determinantes que persistem da história patriarcal e a importância de conscientizar homens e mulheres a respeito dos duplos padrões e das dissonâncias cognitivas entre a proclamação do que é permitido e a ocultação do que, veladamente, exerce censura.

\section{Referências}

Aquino, T. A., Gouveia, V. V., Costa Patrício, K. S., Sarmento da Silva, M. G., Bezerra, L. M., Sousa, V. B., Jr., \& Oliveira Neto, W. M. (2012). O amor entre jovens em tempos de ficar: correlatos existenciais e demográficos. Psicologia: Ciência e Profissão, 32(1), 112-125.

Bardin, L. (2011). Análise de conteúdo. Edições 70.

Barreto Lima, R. A. (2018). Os feminismos e suas vozes: uma leitura junguiana das experiências de mulheres participantes de coletivos feministas (Dissertação de mestrado, Pontifícia Universidade Católica de São Paulo).

Bersamin M. M., Zamboanga B. L., Schwartz S. J., Donnellan M. B., Hudson M., Weisskirch R. S., \& Caraway S. J. (2014). Risky business: is there an association between casual sex and mental health among emerging adults? Journal of Sex Research, 51(1), 43-51.

Carelli, A. R. (2013). A sexualidade humana do passado ao presente. In A. Diehl \& D. L. Vieira, (Org.), Sexualidade: do prazer ao sofrer (pp. 1-38). Roca.

Conley,T.,Ziegler,A., \&Moors,A. (2012). Backlashfromthebedroom:stigmamediatesgenderdifferencesinacceptance of casual sex offers. Psychology of Women Quarterly, 37(3), 392-407. https://doi.org/10.1177/0361684312467169.

Del Priore, M. (2011). Histórias íntimas: sexualidade e erotismo na história do Brasil. Planeta.

Figueiredo, L. B. (2016). Tinderelas: busca amorosa por meio de aplicativos para smatphones (Tese de doutorado). https://tede2.pucsp.br/bitstream/handle/18981/2/L\%C3\%ADgia\%20Baruch\%20de\%20Figueiredo.pdf

Goldenberg, M. (2014). Há sexo casual para mulheres? Folha de São Paulo. http://wwwl.folha.uol.com.br/fsp/ equilibrio/151652-ha-sexo-casual-para-as-mulheres.shtml.

Goldenberg, M. (2015). Sexo. Record.

Hite, S. (1976). The Hite Report: a nationwide study off female sexuality. Dell Publishing

Jonason, P. K. (2013). Four functions for four relationships: consensus definitions of university students. Archives of Sexual Behavior, 42(8), 1407-1414. https://doi.org/10.1007/s10508-013-0189-7. 
Jonason, P. K., Hatfield, E., \& Boler, V. M. (2015). Who engages in serious and casual sex relationships? An individual differences perspective. Personality and Individual Differences, 75, 205-209. https://doi.org/10.1016/ j.paid.2014.11.042.

Jota, F. (2008). Entre o escrito e o dito: dilemas da subjetividade feminina na contemporaneidade: o sexo casual em análise (Dissertação de mestrado). http://repositorio.unb.br/bitstream/10482/3463/1/2008_FernandaSchieber SaudeVilasBoasOliveiraJota.pdf.

Jung, C. G. (1971). Psychological types. Princeton University Press. (Trabalho original publicado em 1921).

Jung, C. G. (2011). O eu e o inconsciente: OC 7/2. Vozes. (Trabalho original publicado em 1928).

Kinsey, A., Pomeroy, B. W., Martin, E. C., \& Gebhard, H. P. (1954). A conduta sexual da mulher. Ateneu.

Lambert, W. W., \& Lambert, W. E. (1968). Curso de psicologia moderna: psicologia social. Zahar.

Lipovetsky, G. (2007). A terceira mulher: permanência e revolução do feminino. Companhia das Letras.

Master, W. H., \& Johnson, V. E. (1984). A resposta sexual humana. Roca.

Navarro Lins, R. (2015). Sexo casual [Post em blog]. https://reginanavarro.blogosfera.uol.com.br/2015/01/13/ sexo-sem-culpa/

Navarro Lins, R. (2018). Novas formas de amar: grandes transformações nos relacionamentos amorosos. Planeta.

Nogueira, C. (2001). Feminismo e discurso do gênero na psicologia social. Psicologia \& Sociedade: Revista da Associação Brasileira de Psicologia Social, 13(1), 107-128. http://hdl.handle.net/1822/4117

Palacio, G. J. R. (2014). Mulheres adultas que moram em repúblicas e seus relacionamentos íntimos amorosos: um enfoque junguiano (Dissertação de mestrado, Pontifícia Universidade Católica de São Paulo).

Piscitelli, A. (2009). Gênero: a história de um conceito. In H. B. Almeida, H., \& J. Szwako J. Diferenças, igualdade. (pp. 116-149). Sociedade em Foco.

Poeschl, G., Múrias, C., \& Ribeiro, R. (2003). As diferenças entre os sexos: mito ou realidade? Análise Psicológica, 2(XXI), 213-228.

Ramos, V., Carvalho, C., \& Leal, I. (2005). Atitudes e comportamentos sexuais de mulheres universitárias: a hipótese do duplo padrão sexual. Análise Psicológica, 23(2), 173-185.

Reis, J. (2010). Orgasmocracia: você tem que gozar, muito! [Post em blog]. https://feminismo.org.br/orgasmocraciavoce-tem-que-gozar-muito/1560/

Reiss, I. L. (1964). The scaling of premarital sexual permissiveness. Journal of Marriage and Family, 26(2), 188-198.

Rogers, S., Ludington, J., \& Graham, S. (1997). Motivation \& learning: a teacher's guide to building excitement for learning \& igniting the drive for quality. Peak Learning Systems.

Rubin, G. (1986). El tráfico de mujeres: notas sobre la 'economía política’ del sexo. Nueva Antropologia, VII(30), 95-145.

Scott, J. W. (1986). Gender: a usefull category of historical analyses. The American Historical Review, 91(5), 1053-1075.

Soster, A. P., \& Kastro, E. K. (2018). Sexo casual: autoestima e busca de sensações sexuais em jovens universitárias. Psicologia, Saúde e Doenças, 19(1), 18-25.

Tinoco, D. (2016). Antídoto à rivalidade: sororidade, substantivo feminino. O Globo. http://hdl.handle. net/10438/16307.

Vandenbos, G. R. (Ed.). (2010). Dicionário de psicologia da APA - American Psychological Association. Artmed.

Wahba L. L. (2016). Snow White took a bite of the poisoned apple... but what about today? Journal of Analytical Psychology, 61(2), 255-262.

Wentland, J. J., \& Reissing, E. (2014). Casual sexual relationships: Identifying definitions for one night stands, booty calls, fuck buddies, and friends with benefits. The Canadian Journal of Human Sexuality, 23(3), 167-177. https://doi.org/10.3138/cjhs.2744. 


\section{Liliana Liviano Wahba}

Pontifícia Universidade Católica de São Paulo (PUC-SP), São Paulo - SP, Brasil.

E-mail: lilwah@uol.com.br

(1) https:// orcid.org/0000-0002-6316-2010

Juliana Bonetti Simão

Pontifícia Universidade Católica de São Paulo (PUC-SP), São Paulo - SP, Brasil.

E-mail: julianabonettisimao@gmail.com

(1) https://orcid.org/0000-0002-3425-2631

Endereço para envio de correspondência:

Avenida Macuco, 184, apto. 53, Moema. CEP: 04523-000. São Paulo - SP. Brasil.

Recebido 11/09/2018

Aceito 06/11/2019

Received 11/09/2018

Approved 06/11/2019

Recibido 11/09/2018

Aceptado 06/11/2019

Como citar:Wahba, L. L., \& Simão, J. B. (2020). Sexo Casual: Motivações, Atitudes e Comportamentos de Homens e Mulheres Heterossexuais Adultos. Psicologia: Ciência e Profissão, 40, 1-15.

https://doi.org/10.1590/1982-3703003213871

How to cite:Wahba, L. L., \& Simão, J. B. (2020). Casual Sex: Motivations, Attitudes and Behaviors of Heterosexual Men and Women. Psicologia: Ciência e Profissão, 40, 1-15. https://doi.org/10.1590/1982-3703003213871

Cómo citar:Wahba, L. L., \& Simão, J. B. (2020). Sexo Casual: Motivaciones, Actitudes y Comportamientos de Hombres y Mujeres Heterosexuales Adultos. Psicologia: Ciência e Profissão, 40, 1-15.

https://doi.org/10.1590/1982-3703003213871 